\title{
Bread-in-pandemic voting: forecasting the 2020 United States presidential election with the Bread and Peace model
}

\author{
Drew M Thomas \\ <dmt107@imperial.ac.uk>
}

November 17, 2020

\begin{abstract}
The Bread and Peace model of US presidential elections estimates VOTE, the incumbent's party's share of the major-party vote, as a function of rates of personal-income growth and military fatalities during the incumbent president's term. I replicate past work fitting the model to elections since 1952, confirming that income growth and war deaths account for most variation in VOTE. Using data available as of the end of October, I develop 5 income-growth forecasts for Donald Trump's presidential term and use them to forecast Trump's share of the two-party vote in the 2020 election. My 5 forecasts range from $49.3 \%$ to $56.1 \%$ with a mean of $53.0 \%$, notably higher than final polling averages of $45.6 \%-46.2 \%$ and the preliminary election result of $48 \%$. An idiosyncratic factor such as the sitting president's impeachment might account for the model overrating Donald Trump's popular-vote performance.
\end{abstract}

\section{Contents}

\begin{tabular}{lll}
\hline & Introduction & 1
\end{tabular}

2 Definition of the Bread and Peace model 2

3 Data

$3.1 \quad$ Military fatalities and population . . . . . . . . . . . . . . . . . . . . . . 2

3.2 Real, disposable personal income per capita . . . . . . . . . . . . . . . . . . . . . . . . . 3

3.3 Presidential election results . . . . . . . . . . . . . . . . . . . . . . . . . . . . . 3

3.4 Preprocessed-data repository . . . . . . . . . . . . . . . . . . . . . . 3

4 Fitting the model to past elections 3

4.1 Preprocessing the data . . . . . . . . . . . . . . . . . . . . . . . 3

4.2 Fitted model . . . . . . . . . . . . . . . . . . . . . . . . . . . . . 5

4.3 Replication of Hibbs's Bread and Peace fits . . . . . . . . . . . . . . . . . . . . . . . 5

5 Applying the model to the 2020 presidential election 8

5.1 Forecasting $G$, FATALITIES, and VOTE for the 2020 election . . . . . . . . . . . . . . . . . . . 8

5.2 Summary of forecasts . . . . . . . . . . . . . . . . . . . . . . . . . 12

5.3 Comparison to polling averages . . . . . . . . . . . . . . . . . . . . . . 13

5.4 Comparison to initial, incomplete election results . . . . . . . . . . . . . . . . . . . . . . 13

\begin{tabular}{|ll|}
\hline 6 & Conclusion \\
\hline
\end{tabular} 


\section{Introduction}

The Bread and Peace model is a parsimonious model of how voters in US presidential elections split their votes between the Democratic and Republican candidates. In developing the model, its creator Douglas A Hibbs concluded that [1, p. 635]

postwar aggregate votes for president are well explained by just two objectively measured fundamental determinants: (1) weighted-average growth of per capita real disposable personalincome over the term, and (2) cumulative US military fatalities due to unprovoked, hostile deployments of American armed forces in foreign wars.

With the model accounting for only personal-income growth and war deaths, the 2020 US presidential election is an opportunity to test the model in tempestuous times. The 2020 election took place in the wake of, and during, the unusual society-wide disruptions of $(i)$ a once-in-a-century pandemic, $(i i)$ presidentially endorsed degradation of the Postal Service amid a massive expansion of postal voting, and (iii) the largest street-protest movement in the United States to date. This paper pits the model against these turbulent circumstances by documenting the process of fitting Hibbs's Bread and Peace model from scratch ( $\$ 2-84$, making simple forecasts of disposable personal income in the US and of US military fatalities through Q4 2020 (\$5.1), feeding those forecasts into a Bread and Peace model to make predictions about the DemocraticRepublican split of the popular vote $(\$ 5.2)$, and comparing those forecasts against polls $(\$ 5.3)$ and preliminary election results $(5.4$.

\section{Definition of the Bread and Peace model}

The core of the Bread and Peace model is a linear regression of VOTE, the incumbent party's percentage of the two-party vote in a presidential election, against a measure $G$ of income growth and a cumulative measure FATALITIES of deaths of US military personnel:

$$
\mathbb{E}[\mathrm{VOTE}]=\alpha+\beta_{1} G+\beta_{2} \text { FATALITIES }
$$

where $G$ and FATALITIES are both taken over the presidential term that spans the election.

Income growth $G$ is the exponentially-weighted moving average, with additional parameter $\lambda$ denoting the "lag weight", of "the quarter-to-quarter log-percentage change expressed at annual rates" of real, disposable personal income (RDPI) per capita during the pre-election presidential term [1, p. 636]. An endnote adds that for "the election quarter" itself "the lag weight $\left(j=0, \lambda^{j}=1\right)$ is scaled down to $1 / 3$ because of the within-quarter date of presidential elections" [1, p. 639]. In mathematical terms, for a given election,

$$
G \equiv \frac{\frac{400}{3} \ln \frac{\boldsymbol{R}_{0}}{\boldsymbol{R}_{1}}+\sum_{j=1}^{14} \lambda^{j}\left(400 \ln \frac{\boldsymbol{R}_{j}}{\boldsymbol{R}_{j+1}}\right)}{\frac{1}{3}+\sum_{j=1}^{14} \lambda^{j}}
$$

where $\boldsymbol{R}_{j}$ is RDPI per capita $j$ quarters before the quarter of the election [1, p. 636]. Taking a value between zero and one inclusive, $\lambda$ represents how much voters weight earlier income growth relative to income growth closer to the election. When $\lambda \rightarrow 0$, equation 2 reduces to $G \equiv 400 \ln \left(\boldsymbol{R}_{0} / \boldsymbol{R}_{1}\right)$, so that $G$ captures only election-quarter income growth (representing voters who react to only the most-recent income growth). At the other extreme, when $\lambda=1, G$ is a simple average of quarterly income growth throughout the incumbent president's pre-election term (representing voters who weight every quarter's income growth under the incumbent equally). $\lambda$ complicates the fitting of the model because its value must be estimated alongside those of $\alpha, \beta_{1}$, and $\beta_{2}$, which cannot be accomplished with a conventional linear regression.

FATALITIES is the cumulative number of US military fatalities per million US population in unprovoked, hostile wars overseas during the incumbent president's term, with a vital caveat: presidents who [1, p. 635]

inherit[...] unprovoked foreign wars from the opposition party are given a one-term grace period before US fatalities begin to depress the incumbent vote share. Hence Richard Nixon's 
vote in 1972 was not affected by US fatalities in Vietnam because the Vietnam War was inherited from Lyndon Johnson.

Hibbs explicitly counts the US wars in Korea, Vietnam, Iraq, and Afghanistan as wars relevant to the 1952, 1964, 1968, 1976, 2004, 2008, and 2012 elections [1].

\section{Data}

\subsection{Military fatalities and population}

I count US military fatalities by year and by war in two sources of data: the Defense Casualty Analysis System (DCAS), from which I downloaded the public-use data files for 1950-2005 [2] and for 2006 [3], and the iCasualties website, which counts US personnel killed in the US wars in Afghanistan and Iraq from 2001 into 2020 [4].

The DCAS records of the 1950-2005 period assign 16 Korean War deaths a year of death of "0", which I interpret as missing data. As those 16 undated deaths comprise only $0.04 \%$ of the 36,574 Korean War deaths in the dataset, I exclude them. I also discard two time-delayed Vietnam War deaths in the year 2006 (but nonetheless recorded in the 1950-2005 data file).

The DCAS and iCasualties datasets overlap in the years 2001-2006, so one can check how well the datasets agree on each year's total US military deaths in the Afghanistan and Iraq Wars. DCAS records 11, 48, 528, 897, 942, and 918 War on Terror military deaths in the years 2001 through 2006 respectively; iCasualties records 12, 49, 534, 901, 945, and 921 deaths in the Afghanistan and Iraq Wars in the same years. In absolute terms the two time series are extremely similar, so I treat them as interchangeable, and build a 1950-2020 dataset by simply splicing together the DCAS counts for 1950 through 2000 and iCasualties' counts for 2001 onwards.

When normalizing the fatality counts to fatalities per million population, I use the US Bureau of Economic Analysis's quarterly time series of the entire US population [5]. The time series begins in Q1 1947 and Federal Reserve Economic Data publishes it under the name B230RCOQ173SBEA. In previous versions of my analyses, published in October, I instead used the US Census Bureau's National Intercensal tables for 1900-1999 [6] and datasets for 2000 onwards [7, 8, but spliced-together Census time series suffer from a dubious jump in the US population in the year 2000 (9.5 million, versus 1.5 million to 3.2 million in every other post-World War II year).

\subsection{Real, disposable personal income per capita}

The US Bureau of Economic Analysis publishes RDPI per capita, available from Federal Reserve Economic Data as the monthly time series A229RX0, starting in 1959 [9, and the quarterly time series A229RX0Q048SBEA, starting in 1947 [10. For consistency with Hibbs's model, and to accommodate the 1952-1960 presidential elections as observations, I use the quarterly series.

After fitting Hibbs's model below, I later use the monthly time series W875RX1 [11] of RDPI excluding current transfer receipts as a measure of RDPI minus government transfers. This pre-transfer income better reflects the direct impact of the COVID-19 pandemic on US residents' incomes. The Bureau supplies this time series only in billions of dollars, not as a per capita series, so I divide it by an interpolated version of the population time series to obtain per capita RDPI excluding current transfer receipts.

\subsection{Presidential election results}

The model's dependent variable VOTE is the incumbent party's candidate's share of all votes won by the Democratic and Republican candidates in each US presidential election. For the 1952-2016 presidential elections, I transcribe the Democratic and Republican parties' national vote totals from Dave Leip's Atlas of U.S. Presidential Elections [12, and compute VOTE as the incumbent party's percentage of the votes cast for either major party. 


\begin{tabular}{rrrcrr}
\hline & & & \multicolumn{3}{c}{ military fatalities attributed to incumbent } \\
\cline { 5 - 6 } year & incum. & pop. (mln.) & relevant war(s) & count & per mln. \\
\hline 1952 & Dem. & 157.99 & Korean & 32,483 & 206.2 \\
1956 & Rep. & 169.42 & none & 0 & 0.0 \\
1960 & Rep. & 182.02 & Vietnam & 8 & 0.0 \\
1964 & Dem. & 192.94 & Vietnam & 389 & 2.0 \\
1968 & Dem. & 201.54 & Vietnam & 35,132 & 175.0 \\
1972 & Rep. & 210.74 & none & 0 & 0.0 \\
1976 & Rep. & 218.92 & Vietnam & 131 & 0.6 \\
1980 & Dem. & 228.69 & none & 0 & 0.0 \\
1984 & Rep. & 237.23 & none & 0 & 0.0 \\
1988 & Rep. & 245.97 & none & 0 & 0.0 \\
1992 & Rep. & 258.28 & none & 0 & 0.0 \\
1996 & Dem. & 270.99 & none & 0 & 0.0 \\
2000 & Dem. & 283.52 & none & 0 & 0.0 \\
2004 & Rep. & 294.33 & Iraq & 1264 & 4.3 \\
2008 & Rep. & 305.62 & Iraq & 2861 & 9.4 \\
2012 & Dem. & 315.09 & Afghanistan & 1514 & 4.8 \\
2016 & Dem. & 324.05 & Afghanistan + Iraq & 247 & 0.8 \\
\hline
\end{tabular}

Table 1: Party of the incumbent president, US population in millions, and cumulative military fatalities attributed to the incumbent presidency in presidential election years, 1952-2016.

\subsection{Preprocessed-data repository}

My files of cleaned and preprocessed data, like the raw, public data files I cite in this section, are publicly available online. My preprocessed data, and $\mathrm{R}$ scripts $\mathrm{mf} . \mathrm{R}$ and analyze.R for preprocessing and analyzing data, are hosted at https://osf.io/p6734/

\section{Fitting the model to past elections}

\subsection{Preprocessing the data}

VOTE is a trivial function of raw vote counts; computing FATALITIES and $G$ is more involved.

The first step in computing FATALITIES is specifying which wars' fatalities voters blame on each incumbent. Table 1 lists which wars' fatalities I expect voters to have attributed to each incumbent presidency. Where Hibbs explicitly states that a war's US fatalities did or did not affect an incumbent administration's vote share, I follow his judgements, but I clarify here some potential ambiguities.

With the extent of open US military engagement in Vietnam somewhat arguable as of 1956, I do not count Vietnam War deaths as electorally relevant to Dwight Eisenhower's first term, but I do count them as electorally relevant to his second term. Dating the beginning of the US-Vietnam war to the 1950s under Eisenhower, I ought in principle to grant the 1961-1965 Democratic administration a grace period for inheriting the war from Eisenhower, and hence zero out FATALITIES for the 1964 election. However, Hibbs effectively treats the Vietnam War as having been initiated by the Kennedy-Johnson administration, writing that US military fatalities "might have affected the 1964" election among others [1, p. 637], and assigning the 1964 election a nonzero FATALITIES value of 0.9 in a 2008 paper [15, p. 9].

As for the $21^{\text {st }}$ century, Hibbs notes a subtlety regarding the Afghanistan War 1, p. 635]. Because George W Bush initiated that war in response to the terrorist attacks of 11 September, Hibbs treats the US war in Afghanistan as provoked under Bush's tenure, and infers that voters in 2004 and 2008 did not hold Bush responsible for US personnel killed in Afghanistan. However, Hibbs judges the continuation of 


\begin{tabular}{cccrrr}
\hline parameter & & \multicolumn{2}{c}{ parameter estimate } \\
\cline { 1 - 1 } \cline { 5 - 6 } parameter description & symbol & & estimate \pm std. error & $p$ value \\
\hline constant & $\alpha$ & & $45.0 \pm 1.3$ & $<0.001$ \\
coefficient on $G$, weighted average RDPI growth & $\beta_{1}$ & & $3.48 \pm 0.52$ & $<0.001$ \\
coefficient on FATALITIES, cumulative war deaths & $\beta_{2}$ & & $-0.047 \pm 0.011$ & 0.001 \\
lag weight for time-discounting of RDPI growth & $\lambda$ & & $0.85 \pm 0.09$ & $<0.001$ \\
\hline
\end{tabular}

Table 2: The Bread and Peace model fitted to the 17 US presidential elections of 1952-2016.

the war under Obama to be effectively unprovoked, so "under the Bread and Peace Model those [post-2008] fatalities [would] affect negatively the Democratic Party's presidential vote in the 2012 election" [1, p. 635]. Finally, in Obama's second term, I assume that war deaths in both Afghanistan and Iraq would be counted against Obama, with the Afghanistan War remaining effectively a war of choice, and the one-term grace period having been used up for the Iraq War inherited from Bush's administration.

Having decided which wars' deaths to attribute to each administration, I take a weighted sum of those wars' deaths over an administration's four main calendar years (e.g. 2013 through 2016 for Obama in the lead-up to the 2016 election) to produce a total body count for each presidential term (table 1 s penultimate column). When summing deaths during a term, military deaths in the term's first 3 years receive full weight, but the final year's deaths receive a weight of only $11 \div 12$, to accommodate December happening after the election in an election year. Dividing an administration's total by the election-year US population in millions then gives FATALITIES, the rate of election-influencing military fatalities per million population (table $1 \mathrm{~s}$ last column).

It is impossible to separate the calculation of $G$ from the fitting process, because $G$ depends on the value of the model parameter $\lambda$, and the fitting process estimates $\lambda$ 's value. Nonetheless, it is feasible to pre-compute the value of the $\log$ ratios $\ln \left(\boldsymbol{R}_{0} / \boldsymbol{R}_{1}\right)$ and $\ln \left(\boldsymbol{R}_{j} / \boldsymbol{R}_{j+1}\right)$, as $\boldsymbol{R}$ is just the time series of RDPI per capita.

\section{2 $\quad$ Fitted model}

Were $\lambda$ known, fitting the model would be trivial: one could compute $G$ for each election according to eq. 2. then fit eq. 1 as an ordinary least squares (OLS) linear regression. To address the problem that $\lambda$ is an unknown parameter in practice, I nest the trivial fitting step inside a grid search of $\lambda$ values. That is, I first take $\lambda=0$, compute $G$ with eq. 2, and fit eq. 1 1 by linear regression; I repeat the process of computing $G$ and fitting eq. 1 by regression for a series of other, increasing $\lambda$ values; finally, I take the $\lambda$ value that produces the closest-fitting regression as my best estimate of $\lambda$. I also read off the best estimates of $\alpha$, $\beta_{1}$, and $\beta_{2}$ from the closest-fitting regression.

That fitting procedure gives the results in table $2 \alpha$ is about 45 , signalling that a peaceful presidency with no income growth could expect to win about $45 \%$ of the major-party votes, and so would likely lose. In reality presidents consistently oversee some income growth; with $\lambda=0.85, G$ ranges from the Great Recession low of 0.17 in 2008 to a high of 4.39 in 1964, averaging 2.34 . $\beta_{1}$ is clearly positive, implying that voters reward such growth by swinging towards the incumbent's party, and, taking $\beta_{1}=3.48$, a peaceful presidency with typical income growth $(G=2.34)$ could expect to win about $53 \%$ of the two-party votes, which is normally sufficient to win. Dead US military personnel in unprovoked wars, however, appear to have their own negative impact on the incumbent. $\beta_{2}$ is negative, and for a high body count comparable to those for the Korean War in 1952 or the Vietnam War in 1968 (FATALITIES $\approx 190$ ), the model's $\beta_{2}$ estimate of -0.047 translates to a loss of 8.9 percentage points of the major-party votes.

Monte Carlo simulation supplies the parameter estimates' standard errors. I generate 10,000 synthetic datasets with the same $G$ and FATALITIES as the actual data, but with every observation of VOTE replaced with a randomly sampled value from a normal distribution with a mean given by eq. 1 and a standard deviation of 2.60 percentage points (the sample standard deviation of the fitted model's residuals). Applying 


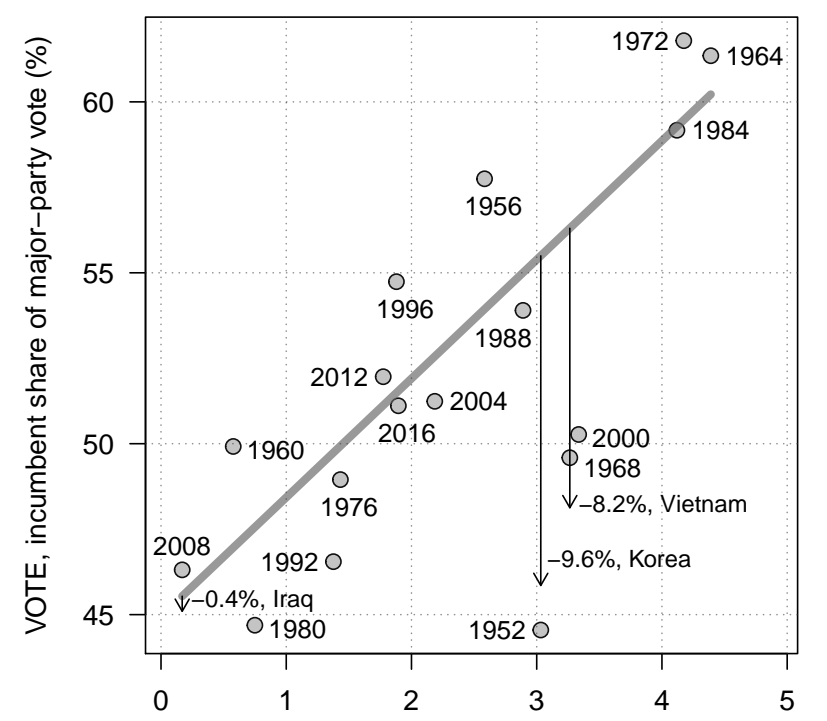

G, weighted-average log-percentage income growth

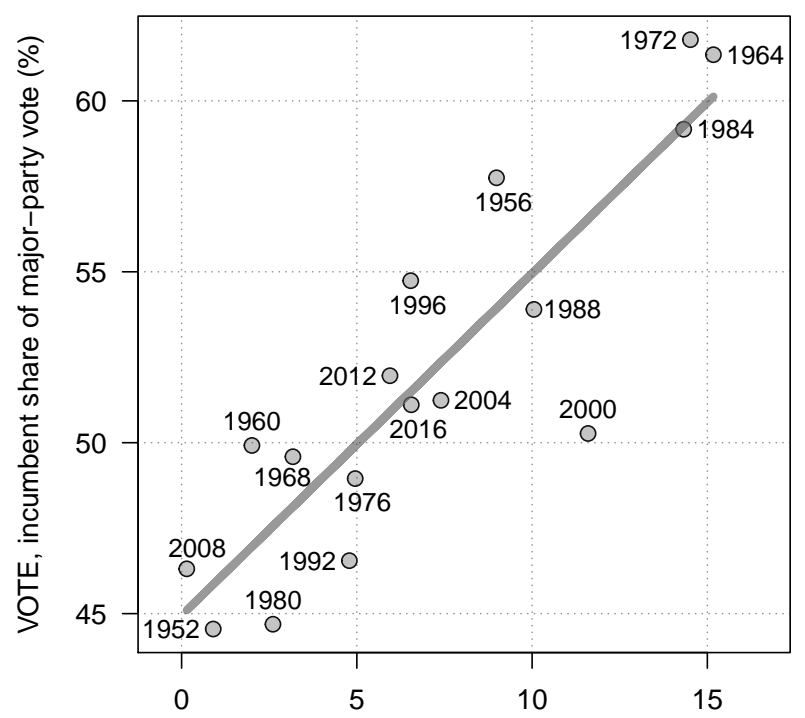

$\beta_{1} G+\beta_{2}$ FATALITIES, combined growth and fatalities

Figure 1: Incumbent share of major-party vote in US presidential elections, 1952-2016, versus the Bread and Peace model fit. Both panels show the same data and fit; the left panel separates out the expected influences of income growth (solid line) and of military fatalities (descending arrows; expected war-death impacts smaller than 0.4 percentage points are omitted), whereas the right panel combines both influences. Compare figs. 1 \& 2 of Hibbs's 2012 paper [1, pp. $637 \& 638]$.

the fitting process to each of the 10,000 synthetic datasets gives 10,000 estimates of every parameter, and I take the standard deviation of each parameter's 10,000 estimates as the parameter's standard error.

Figure 1 compares the fitted model to actual election results. VOTE's association with income growth and military fatalities is visible, although substantial noise is visible as well. The model's overall root-meansquared (RMS) error is 2.53 percentage points, but the model fits the dataset's latest 4 elections more closely, and its match to the 2016 presidential election is excellent.

\subsection{Replication of Hibbs's Bread and Peace fits}

\subsubsection{Comparison of overall statistical results}

My version of the Bread and Peace model can be compared to Hibbs's past versions. Table 3 compares Hibbs's parameter estimates to those I obtain when fitting the model to different ranges of elections. Hibbs's earliest outline of the model [13] was fundamentally different to later versions in that it included only weighted RDPI growth, not military fatalities, and so its atypically low $\lambda(0.8$, versus Hibbs's later estimates of $0.87-0.95)$ and closeness of fit (its RMS error was more than twice that of Hibbs's later fits) may be put down to its omission of the military-fatalities factor. However, his 4 later iterations of the model are broadly comparable, so I re-fit the model to the 4 series of elections (1952-1996, 1952-2004, 1952-2008, and 1952-2012) he used, enabling a comparison of my fits to his.

My parameter estimates are statistically and practically similar to Hibbs's $21^{\text {st }}$-century estimates. We both find that each log-percentage point of weighted average RDPI growth is associated with 3-4 more percentage points of the major-party vote share $\left(\beta_{1} \approx 3.5\right)$; that voters emphasize more-recent RDPI growth when evaluating a presidency, but not overwhelmingly $(0.85 \lesssim \lambda<0.95)$; that military fatalities accompany worse incumbent performance $\left(\beta_{2}<0\right)$ but that their association with worse performance is relatively weak $\left(\left|\beta_{2}\right| \ll 1\right)$; and that the incumbent party is liable to lose the popular vote in the absence of RDPI growth $(\alpha \approx 46<50)$. 


\begin{tabular}{ccrrrrrrrr}
\hline & & \multicolumn{4}{c}{ parameter estimates } & & \multicolumn{2}{c}{ fit statistics } \\
\cline { 5 - 6 } version of the model & elections & $\alpha$ & $\beta_{1}$ & $\beta_{2}$ & $\lambda$ & & $R^{2}(\%)$ & RMS err. \\
\hline Hibbs, 1982 [13] & $1952-1980$ & 45.7 & 3.30 & not used & 0.8 & & 63 & 5.09 \\
Hibbs, 2000 [14] & $1952-1996$ & 46.1 & 4.1 & $*$ & 0.95 & & 90 & 1.97 \\
Hibbs, 2008 [15] & $1952-2004$ & 46.2 & 3.55 & -0.052 & 0.909 & & 87 & 2.38 \\
Hibbs, 2012 [1] & $1952-2008$ & 45.7 & 3.64 & -0.05 & 0.90 & & 89 & 2.2 \\
Hibbs, 2014 [16] & $1952-2012$ & 47.1 & 3.1 & -0.05 & 0.87 & & $\approx 85$ & 2.4 \\
this paper & $1952-1996$ & 44.1 & 4.22 & -0.056 & 0.89 & & 87 & 2.13 \\
this paper & $1952-2004$ & 44.4 & 3.60 & -0.046 & 0.84 & & 76 & 2.73 \\
this paper & $1952-2008$ & 44.9 & 3.49 & -0.047 & 0.85 & & 77 & 2.67 \\
this paper & $1952-2012$ & 45.0 & 3.47 & -0.047 & 0.85 & & 77 & 2.60 \\
this paper & $1952-2016$ & 45.0 & 3.48 & -0.047 & 0.85 & & 77 & 2.53 \\
\hline
\end{tabular}

Table 3: Summary comparison of Hibbs's statistical Bread and Peace results to mine. ${ }^{*}$ In his 2000 model, Hibbs used the absolute number of military fatalities as a regressor instead of the relative number, so that version's " $\beta_{2}$ " of -0.37 is not directly comparable to the others'.

My versions of the model differ from Hibbs's by fitting the data less closely. Hibbs found that the model consistently accounted for at least $85 \%$ of the variance in major-party vote splits, but I find that in recent years it consistently accounts for only $77 \%$ of the variance. Also, my parameter estimates fluctuated less than Hibbs's when adding the 2012 election to the 1952-2008 dataset.

\subsubsection{Comparison of my data to Hibbs's}

Because Hibbs and I are using identical models, differences in our datasets should explain the differences between our results.

I can diagnose one difference in datasets with Hibbs's 2012 paper, which refers to cumulative US military fatalities "in Korea at the time of the 1952 election" of "29,260 or 190 per millions of population", and "in Vietnam at the 1968 election" of "28,900 or 146 per millions of population" 1, p. 637]. My estimates differ: I count 32,483 deaths (or 206 per million) in Korea through November 1952 and 35,132 deaths (or 174 per million) through November 1968 in Vietnam. My approximate method of counting deaths (counting all election-year deaths but downscaling them by $1 \div 12)$ partly explains my higher numbers; if I count deaths more precisely from inauguration day to election day (non-inclusive), I count only 32,292 (or 204 per million) in Korea and 34,895 (or 173 per million) in Vietnam. This accounts for only a little of the difference between Hibbs's FATALITIES and mine, however.

A newer deck of slides from Hibbs affords a more comprehensive comparison of datasets, as one of the slides tabulates his raw data for the 1952-2012 elections [16, p. 40]. Table 4 sets Hibbs's data alongside mine. The juxtaposition reveals that our datasets disagree not only about FATALITIES, but about $G$ and even the dependent variable VOTE. Hibbs and I agree on VOTE to within rounding error for every presidential election since 1996, but disagree for most of the pre-1996 elections. We also disagree consistently about $G$, with my values tending to be kinder to the incumbent, and the disagreement is not just because of Hibbs using a different $\lambda$ estimate $(0.87$ [16, p. 34]), because disagreement is still evident when I recalculate $G$ using Hibbs's $\lambda$. Possibly the discrepancies between our datasets are down to aggressive rounding on Hibbs's part while computing the 3 variables, and post hoc revisions to RDPI data by the Bureau of Economic Analysis. 


\begin{tabular}{|c|c|c|c|c|c|c|c|}
\hline \multirow[b]{3}{*}{ year } & & & \multicolumn{3}{|c|}{$G$} & & \\
\hline & \multicolumn{2}{|c|}{ VOTE } & & \multicolumn{2}{|c|}{ me } & \multicolumn{2}{|c|}{ FATALITIES } \\
\hline & Hibbs & me & Hibbs & $\lambda=0.85$ & $\lambda=0.87$ & Hibbs & me \\
\hline 1952 & 44.7 & 44.55 & 2.6 & 3.0325 & 3.0406 & 190 & 205.6 \\
\hline 1956 & 58.0 & 57.75 & 2.9 & 2.5836 & 2.5566 & 0 & 0.0 \\
\hline 1960 & 49.9 & 49.92 & 0.9 & 0.5768 & 0.6133 & 0 & 0.0 \\
\hline 1964 & 61.2 & 61.35 & 4.4 & 4.3904 & 4.3059 & 1 & 2.0 \\
\hline 1968 & 49.4 & 49.59 & 2.9 & 3.2644 & 3.3188 & 146 & 174.3 \\
\hline 1972 & 61.8 & 61.79 & 3.9 & 4.1745 & 4.0736 & 0 & 0.0 \\
\hline 1976 & 49.0 & 48.95 & 0.9 & 1.4324 & 1.3492 & 2 & 0.6 \\
\hline 1980 & 44.8 & 44.69 & -0.9 & 0.7495 & 0.8205 & 0 & 0.0 \\
\hline 1984 & 59.1 & 59.17 & 3.9 & 4.1195 & 3.9993 & 0 & 0.0 \\
\hline 1988 & 53.8 & 53.90 & 2.7 & 2.8907 & 2.8540 & 0 & 0.0 \\
\hline 1992 & 46.4 & 46.55 & 0.7 & 1.3764 & 1.3114 & 0 & 0.0 \\
\hline 1996 & 54.7 & 54.74 & 1.2 & 1.8797 & 1.8611 & 0 & 0.0 \\
\hline 2000 & 50.3 & 50.27 & 2.5 & 3.3349 & 3.3412 & 0 & 0.0 \\
\hline 2004 & 51.2 & 51.24 & 1.9 & 2.1860 & 2.1548 & 4 & 4.3 \\
\hline 2008 & 46.3 & 46.31 & -0.2 & 0.1691 & 0.3150 & 14 & 9.4 \\
\hline 2012 & 52.0 & 51.96 & 0.8 & 1.7744 & 1.7364 & 5 & 4.8 \\
\hline 2016 & & 51.11 & & 1.8951 & 1.9738 & & 0.8 \\
\hline
\end{tabular}

Table 4: Comparison of Hibbs's 2014 data [16, p. 40] to my current data.

\section{Applying the model to the 2020 presidential election}

\subsection{Forecasting $G$, FATALITIES, and VOTE for the 2020 election}

The fitted Bread and Peace model reduces the problem of forecasting the 2020 presidential election's twoparty split to the two sub-problems of forecasting $G$ and forecasting FATALITIES through Q4 2020. Feeding such forecasts of $G$ and FATALITIES into the model produces a forecast of the two-party vote split VOTE.

Beginning with FATALITIES, one might forecast deaths of US military personnel through Q4 2020 in the Afghanistan and Iraq Wars. The US population is 330 million [5, and my $\beta_{2}$ estimate is -0.047 , according to which $|330 \div-0.047| \times 0.1=702$ military fatalities in Afghanistan or Iraq would be necessary to shift VOTE by even a tenth of a percentage point. By contrast, only 104 US military personnel died in the Afghanistan and Iraq Wars in 2017 through 2019, and a further 21 died in 2020 up to 24 October 2020 [4. Extrapolating through the rest of this year, the likely total of such deaths is 125-140 through Q4 2020, whereas a total in the multiple hundreds is implausible, especially given the Department of Defense's recent announcement of pre-election troop withdrawals [17. One could therefore take FATALITIES $=130 \div 330=0.39$ with confidence that a large relative error in that forecast is both unlikely, and unlikely to much affect the final vOTE forecast.

In previous analyses I took that approach, using nonzero FATALITIES values of 0.41 and 0.39 . But, on reflection, I prefer taking FATALITIES to be zero, on the grounds that Trump would have a one-term grace period after inheriting the Afghanistan and Iraq Wars from Barack Obama. (This is not a post hoc fix to improve the model's fit in light of the initial 2020 election results; switching to a FATALITIES of zero actually worsens the fitted model's 2020 forecasts.) That a Republican president (Bush) started the wars does not deprive Trump of the grace period; in my dataset, a Republican president (Eisenhower) started the Vietnam War, but I nonetheless recognize that a subsequent Republican president (Nixon) enjoyed a first-term grace period even as he perpetuated the war.

The more difficult forecast is then forecasting $G$, because it amounts to forecasting RDPI per capita in Q4 of 2020, and 2020 is without precedent in the income time series for its volatility, with RDPI per capita having leapt by $\$ 4,533$ from Q1 to Q2 and then dipped by $\$ 2,255$ from Q2 to Q3 (fig. 2). It would be 


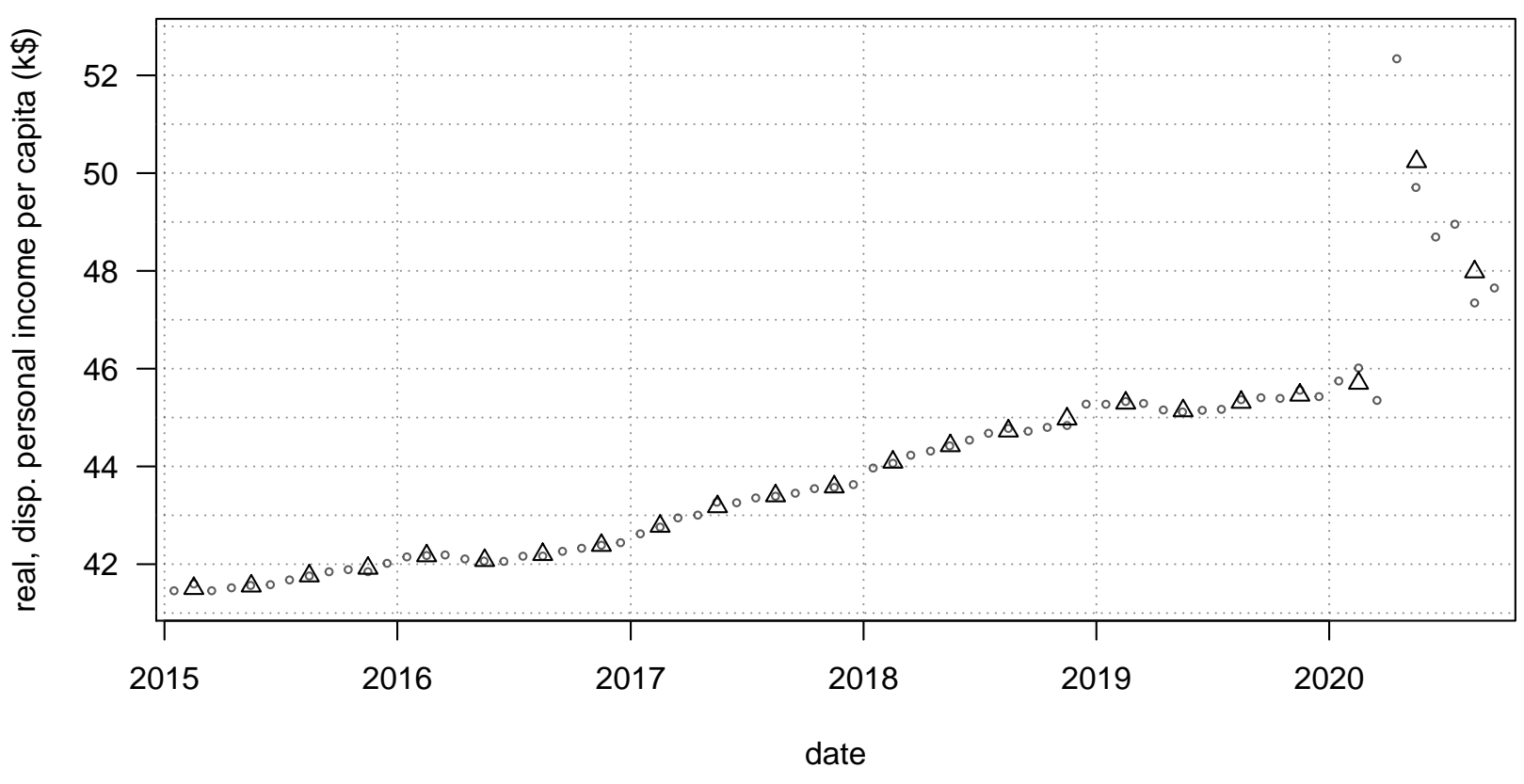

Figure 2: RDPI per capita from 2015 onwards. Small circles and large triangles denote monthly [9] and quarterly [10] data respectively.

unrealistic to forecast $G$ 's precise trajectory with confidence, so instead of generating one forecast of RDPI per capita and $G$, I generate several, to try to represent a reasonable range of possible outcomes.

\subsubsection{Crude forecasts of $G$}

Figure 2 plots the monthly and quarterly RDPI time series, starting from the lead-up to the 2016 election. (An income dip in Q2 2016 and anaemic growth in Q3 2016 go some way to accounting for Hillary Clinton's loss.) As of mid-November 2020, the quarterly data and monthly data end at the same time: the end of Q3, and the end of September. The simplest (crudest) extrapolation is arguably to take that most recent datum - September's value of $\$ 47,650$ - and use it as the forecast for October through December. Taking $\$ 47,650$ as RDPI per capita in Q4 of 2020 produces a $G$ of 3.20 for this autumn's election, which my fitted model translates to Trump winning $56.1 \%$ of the two-party vote. Trump having won the previous election with only $48.9 \%$ of the two-party vote, he would seem virtually certain to win in this scenario.

Another simple forecast, less optimistic, comes from taking 2020's monthly low of $\$ 45,351$ in March, and assuming that RDPI per capita falls back to that level in Q4 2020. That implies RDPI per capita of $\$ 45,351$ in $\mathrm{Q} 4$, and hence a $G$ of 1.98 , which the model translates to Trump winning $51.8 \%$ of the two-party vote.

\subsubsection{Forecasting $G$ with pre-transfer income data and timing of CARES Act provisions}

A more rigorous way to forecast RDPI and hence $G$ is to separately quantify and then add together the main short-term influences on RDPI in summer 2020 and autumn 2020: the COVID-19 pandemic itself, and the income-injecting provisions of the CARES (Coronavirus Aid, Relief, and Economic Security) Act.

To quantify and forecast the direct impact of the pandemic on income, I now bring in the Bureau of Economic Analysis's time series of RDPI excluding current transfer receipts [11, which approximately represents how US residents' income has changed after subtracting government transfers. Figure 3 plots that time series for 2015 to date, illustrating how the pandemic might have driven down US residents' incomes absent government relief. (Strictly, current transfer receipts are "[p]ayments by business and government to persons for which no current services are performed" [18, p. 13], and not just government transfers, but 

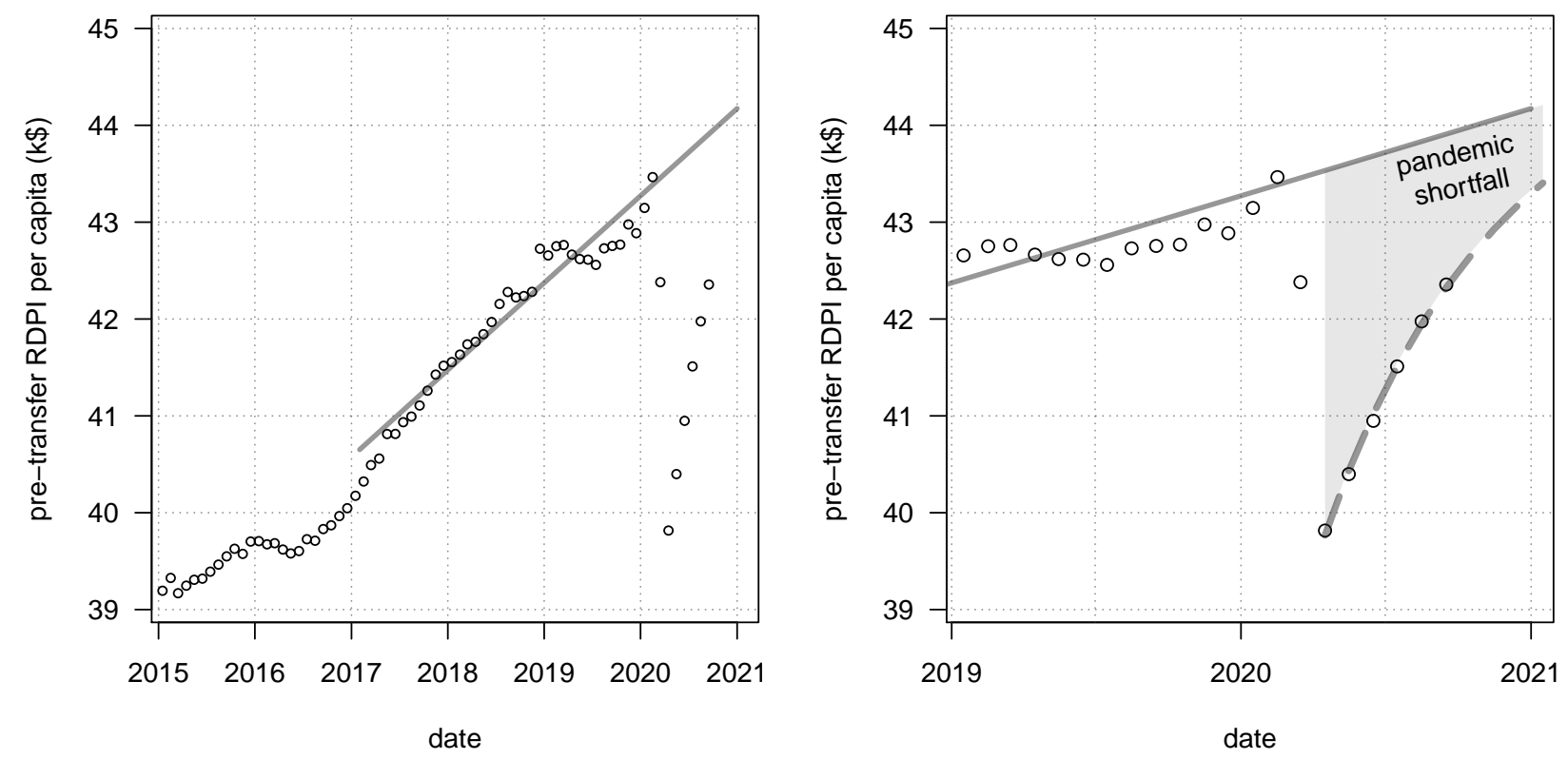

Figure 3: Pre-transfer RDPI per capita from 2015 onwards [11. Straight, sloped lines are an OLS linearregression fit of the trend from February 2017 (Trump's first full month in office) through January 2020 (the latest month with negligible influence from the COVID-19 pandemic). The right panel's dashed curve, an exponential-decay fit through the April-September data towards the straight-line trend, is a possible trajectory of pre-transfer RDPI per capita during the rest of 2020.

government transfers dominate and so for brevity I treat "current transfer receipts" as synonymous with government transfers.) I fit a straight-line trajectory to project how pre-transfer RDPI might have continued growing without the pandemic. To turn that no-pandemic forecast into a with-pandemic forecast, I next assume that without government relief, pre-transfer RDPI would spend the rest of 2020 relaxing towards the no-pandemic forecast in the manner of exponential decay; that is, that pre-transfer RDPI would close a fixed percentage of the remaining gap (between it and the no-pandemic baseline) each month. Fitting that exponential-decay return to trend produces the trajectory in figure 3 s right panel, which erases half of the remaining pandemic-triggered income gap every 121 days.

That establishes a forecast of income excluding government transfers. I now have to add a forecast of transfer income to get a final forecast of RDPI in general. I decompose the problem of forecasting transfer income into two steps, the first being forecasting a no-pandemic baseline level of transfers and the second forecasting temporary pandemic-driven transfers.

Conveniently, per capita transfer income (fig. 4) was rather steady in the months before the COVID-19 pandemic. From January 2018 through February 2020 its annualized average remained in a narrow range of $\$ 2350$ to $\$ 2581$, with a sample standard deviation of only $\$ 57$; I use a linear regression over that period to forecast a no-pandemic baseline of transfer income. The remaining part of transfer income to account for is that provoked by the pandemic, which comes overwhelmingly from the CARES Act.

The two dominant CARES Act supplements to personal income are one-time direct payments known as Economic Impact Payments (EIPs) and enhancements to unemployment benefits [19. A 3 June Treasury press release declared that the EIPs had "been sent to all eligible Americans for whom the IRS has the necessary information", so that source of transfer income was mostly exhausted in July and beyond [20]. As for unemployment benefits, the CARES Act expanded them in three respects: extending unemployment benefits by 13 weeks, making more people eligible for unemployment benefits, and adding $\$ 600$ per week to unemployment benefits. The first two provisions shall continue until the end of 2020, but the last provision ended on 31 July 22, helping to explain the dip in transfer RDPI from July to August. (In the first 

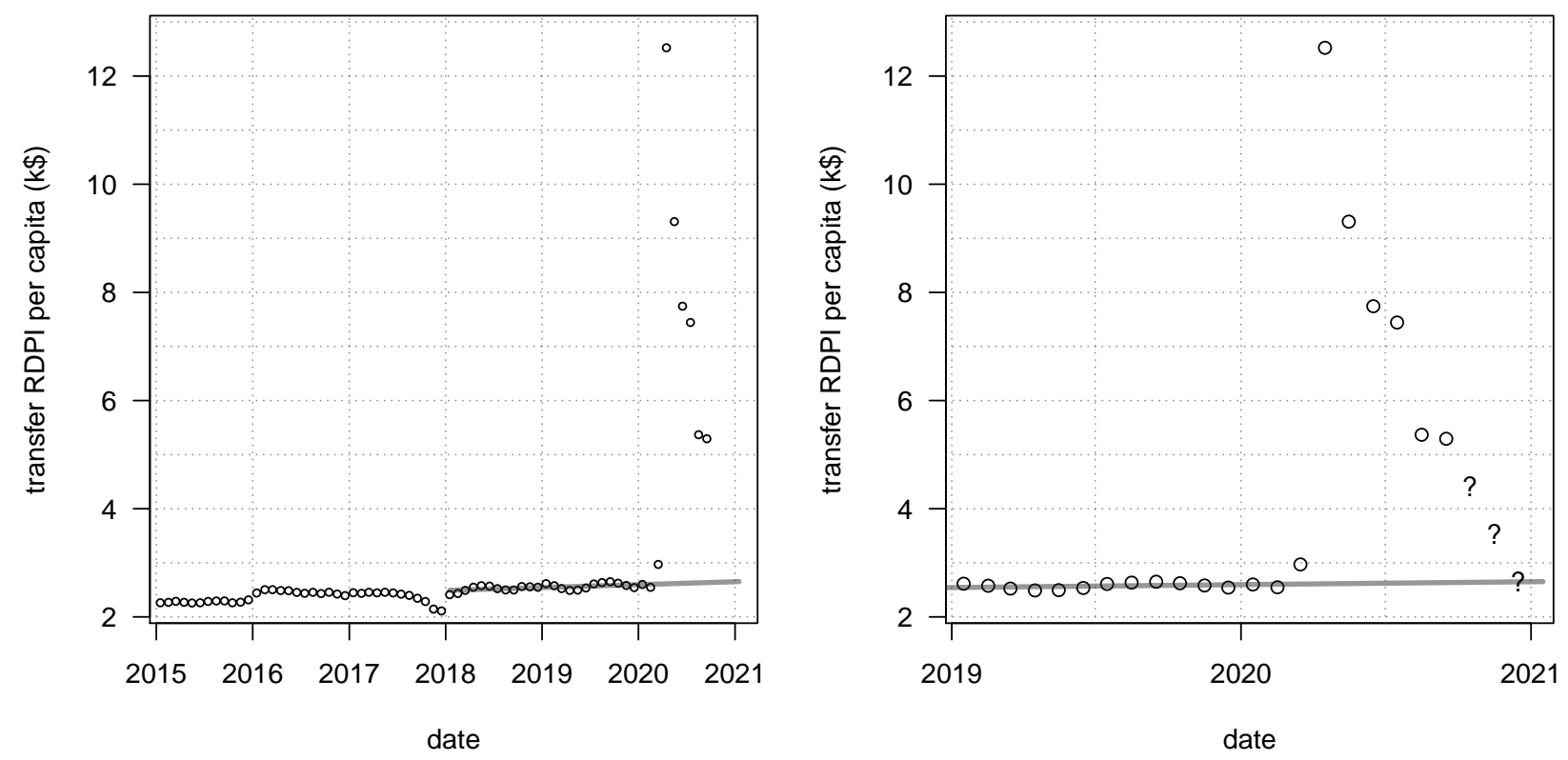

Figure 4: Government-transfer RDPI per capita from 2015 onwards, estimated as total RDPI per capita 9] minus pre-transfer RDPI per capita [11. Straight, sloped lines are an OLS linear-regression fit of the trend from January 2018 through February 2020. Question marks represent a simple monthly forecast.

draft of this paper, I forecasted transfer RDPI per capita for August by assuming it would fall halfway between July's value of $\$ 7458$ and August's baseline forecast of $\$ 2565$, hence $\$ 5012$. The actual value was \$5328.) After August, assuming no passage of a new bill to replenish transfer income, transfer income is likely to decline month on month as the CARES Act's 13-week extension runs out for increasingly many unemployment-benefit recipients.

For Q4, I assume that the gradual expiry of the 13-week unemployment extension engenders a steady loss of transfer income, and hence that transfer RDPI per capita declines on a straight-line trajectory to the baseline, making it $\$ 4412$ in October, $\$ 3530$ in November, and $\$ 2648$ in December. Figure 4 4 s right panel plots this forecast as question marks.

Combining that monthly forecast of transfer income with the monthly forecast of pre-transfer income (based on an exponentially decaying relaxation to a linear upward trend) gives a monthly forecast of RDPI in general which is a roughly linear decline through December (fig. 5). A quarterly average of the monthly RDPI-in-general forecast gives a forecast of $\$ 46,485$ for Q4 2020. That Q4 forecast is higher than Q1's actual RDPI per capita of $\$ 45,702$, despite the forecast relying on the assumption of no new law from Congress supplying further household income support.

Taken as a whole, this forecast leads to a strong $G$ of 2.59 for the 2020 election, close to the 1956 election's $G$ of 2.58. The fitted model translates $G=2.59$ to Trump winning $54.0 \%$ of the two-party vote, superior to the $51.1 \%$ achieved by Clinton's Democratic campaign in 2016. Assuming that Trump's supporters have a relatively advantageous geographical distribution, as they did in 2016, winning $54.0 \%$ of the major-party vote would almost certainly win Trump the 2020 election.

\subsection{3 $G$ implied by Goldman Sachs's April forecast of income}

Goldman Sachs published a research note forecasting the net economic effect of "the virus shock" and the "unusually generous stimulus package" in late April [23]. Among other forecasts, a stacked-bar chart in the note [23, Exhibit 8] presents a quarterly forecast of US disposable personal income through 2020 and 2021, and so implies a particular $G$ for the 2020 election. The chart gives personal-income estimates "relative to 


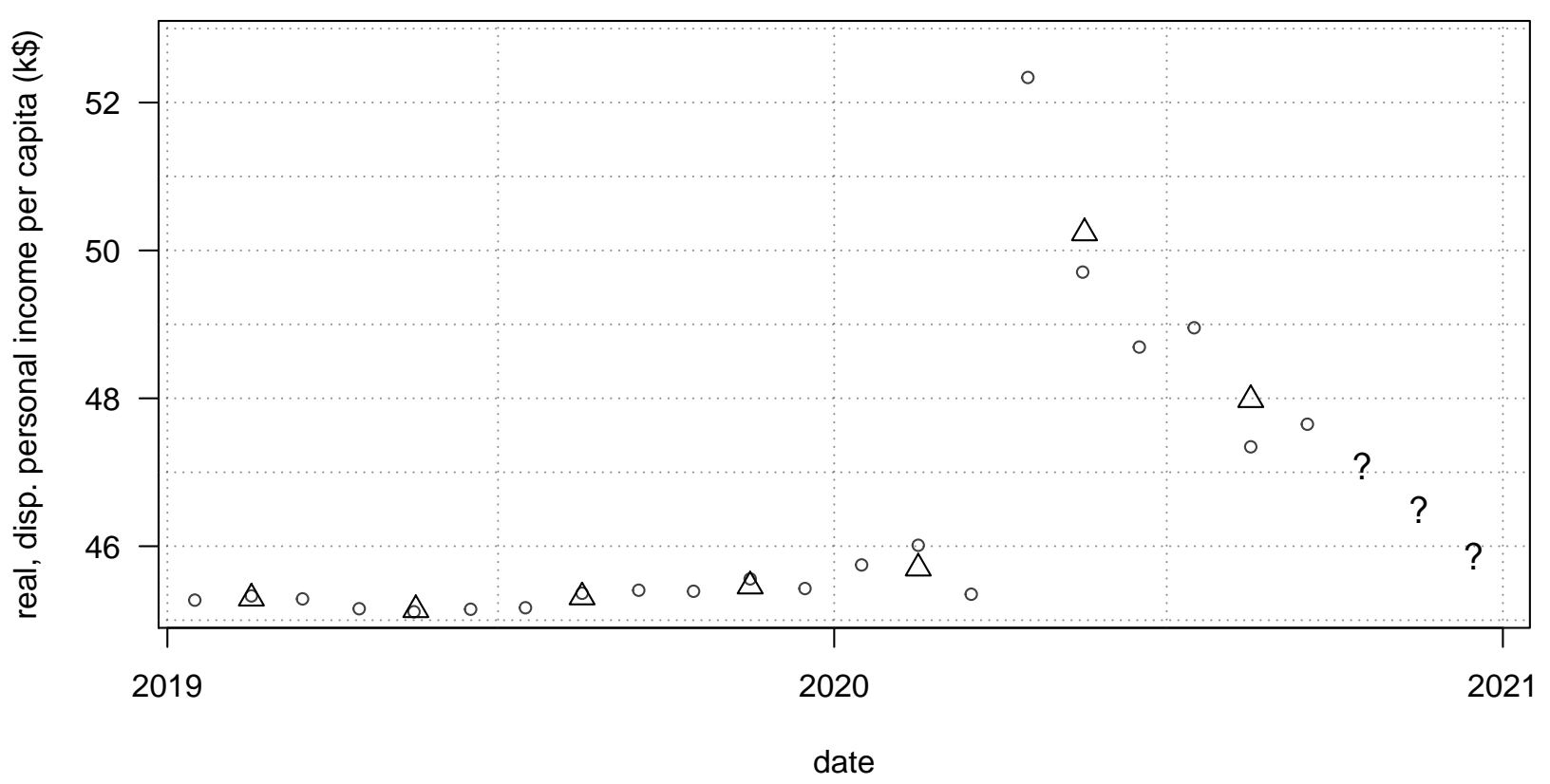

Figure 5: RDPI per capita from 2019 onwards. Small circles, large triangles, and question marks denote monthly observations, quarterly observations, and monthly forecasts respectively.

2019Q4 DPI" 23, Exhibit 8], and for 2020 those estimates are, in chronological order, $-0.4 \%, 4.6 \%, 0.3 \%$ and $-3.1 \%$.

Taking those estimates at face value, RDPI per capita in Q4 2020 is forecast to be $3.1 \%$ lower than Q4 2019 's $\$ 45,459$, immediately implying a Q4 2020 RDPI per capita of $\$ 44,050$ and a $G$ of 1.26 . With $G=1.26$ the fitted model anticipates that Trump would secure $49.3 \%$ of the two-party vote, a slight improvement on the $48.9 \%$ he won in the 2016 presidential election.

However, the Goldman Sachs forecast proved too low in Q1, Q2, and Q3 of 2020. Actual RDPI per capita was slightly higher in Q1 2020 than in Q4 2019 (not slightly lower), was 10.5\% higher (not 4.6\% higher) in Q2 2020 than in Q4 2019, and was 5.5\% higher (not 0.3\% higher) in Q3 2020 than in Q4 2019. That consistent underestimation suggests that one should revise the forecast upwards. How to revise it is an open question; here I convert the Goldman Sachs forecast to quarter-on-quarter (QOQ) RDPI changes, and use those QOQ changes to forecast income and $G$ instead of the original forecast's changes relative to Q4 2019. The Goldman Sachs forecast implies a QOQ change of -3.4\% from Q3 to Q4 of 2020. Applying that to Q3's actual RDPI per capita of $\$ 47,980$ gives a Q4 forecast of $\$ 46,349$, and hence a $G$ of 2.52 . With $G=2.52$ the model expects Trump to win $53.7 \%$ of the two-party vote share.

\subsection{Summary of forecasts}

Table 5 summarizes the 5 forecasts of $G$ and VOTE developed in this section from data available as of 30 October, alongside the forecasts' earlier versions published on 20 October and based on older data available on 1 October. My older forecasts spanned a wide range of values, consistent with an almost-guaranteed loss for Donald Trump (VOTE $=42.5 \%$ ) to a virtually certain win for Donald Trump (VOTE $=54.7 \%$ ). My current forecasts, which benefit from Q3/September data, concentrate more narrowly in the range $49.3 \%$ to $56.1 \%$, with all 5 forecasts suggesting a Donald Trump Electoral College victory (based on his 2016 victory with VOTE $=48.9 \%$ ), and 4 of the 5 forecasting a Trump popular-vote plurality.

Uncertainty about future income is not the only source of uncertainty in the final forecasts. The other major source of uncertainty is everything not included in the Bread and Peace model, such as campaign effects, home-state effects, or the charisma of individual candidates. I quantify the noise from such factors as 


\begin{tabular}{|c|c|c|c|c|}
\hline \multirow[b]{2}{*}{ description } & \multicolumn{2}{|c|}{$G$} & \multicolumn{2}{|c|}{$\operatorname{VOTE}(\%)$} \\
\hline & 1 Oct. & 30 Oct. & 1 Oct. & 30 Oct. \\
\hline crudely extrapolating September income through December & 1.97 & 3.20 & 51.8 & 56.1 \\
\hline crudely extrapolating March income to Q4 & 1.83 & 1.98 & 51.3 & 51.8 \\
\hline forecasting pre-transfer income and transfer income monthly & 1.81 & 2.59 & 51.2 & 54.0 \\
\hline Goldman Sachs forecast, applied directly (rel. to Q4 2019) & -0.69 & 1.26 & 42.5 & 49.3 \\
\hline Goldman Sachs forecast, applied as qtr.-on-qtr. changes & 2.81 & 2.52 & 54.7 & 53.7 \\
\hline
\end{tabular}

Table 5: Summary of this section's current 2020-election forecasts (columns labelled "30 Oct."; FATALITIES $=0$ ) and previously published forecasts relying on older data (columns labelled "1 Oct."; FATALITIES = $0.39)$. All forecasts assume $\lambda=0.85$.

the sample standard deviation of the residuals/errors of my version of the model, and across the 17 elections of 1952-2016, that standard deviation is 2.60 percentage points. If the model expects Trump to get about $53 \%$ of the major-party vote, Donald Trump would have to underperform by about 1.2 standard errors to lose the popular vote to Joe Biden.

2.60 points is an ex post standard error for the model's results; that is, the model's in-sample standard error when income and $G$ are already known with hindsight is 2.60 points. The model's ex ante error can be expected to be worse on average, because of the added influence of uncertainty about future income. To account for that, I quantify the effect of income uncertainty as the sample standard deviation of the 5 VOTE forecasts, which is 2.56 percentage points. Summing that in quadrature with 2.60 percentage points gives an ex ante standard error of 3.65 points. By that measure, not knowing future income worsens the uncertainty in the model's final results by about $40 \%$.

The ex ante standard error can form part of a probabilistic VOTE forecast. Averaging the 5 VOTE forecasts gives a point estimate of $53.0 \%$, so a natural, model-inspired, probabilistic forecast of VOTE is a normal distribution with a mean of $53.0 \%$ and a standard deviation of 3.65 percentage points.

\subsection{Comparison to polling averages}

It is interesting to compare the model-based predictions to final polling averages. The former anticipate a clear Trump lead in votes but the latter gave Biden a clear lead. 270 to Win's average granted Trump 45.8\% of the two-party vote, RealClear Politics's $46.2 \%$, and FiveThirtyEight's only $45.6 \%$ [24. All 3 polling averages are less than the $49 \%-56 \%$ I derive from the Bread and Peace model, and substantially less than the $53 \%$ average of my Bread and Peace forecasts. The 7-point gap between the polling averages and my average forecast is about twice the 3.65-point standard error I estimate for the model.

Taking a probabilistic perspective, FiveThirtyEight's 3 November forecast gave Trump a $10 \%$ chance of winning this year's election, and only a $3 \%$ chance of winning the popular vote in this year's election [25]. By contrast, assuming that the $48.9 \%$ that Trump won of the two-party vote in 2016 is sufficient and necessary for him to win the 2020 election, the Bread-and-Peace-inspired probabilistic forecast implies an $87 \%$ chance of a Trump victory (i.e., $48.9 \%$ is the $13^{\text {th }}$ percentile of a normal distribution with a mean of $53.0 \%$ and a standard deviation of 3.65 points).

That aggregate model-based forecast, along with most of the 5 individual model-based forecasts, are in stark contrast to final polling averages that implied a near-certain Trump loss. In past drafts of this paper I identified 3 possible fates for this discrepancy between polls and my version of the Bread and Peace model. First, that the discrepancy could disappear, though that would have called for an implausibly strong and abrupt swing in the polls. Second, that the model could eventually prove more accurate than the polls. Third, that the polls could eventually prove more accurate than the model, the possibility I found most likely. Which outcome occurs depends on the actual election results. 


\subsection{Comparison to initial, incomplete election results}

As I write, hundreds of thousands of votes remain uncounted in the 2020 presidential election, but 73.2 million votes for Trump and 78.9 million votes for Biden have already been reported [26]. The two-party vote split is $48.13 \%$ to Trump and $51.87 \%$ to Biden, and Trump's percentage is gradually trending downwards. Thus the polls, which did not swing into line with the Bread and Peace model's forecasts, are proving more accurate than most of the model forecasts. Despite underrating Trump's support as they did in 2016, the polls correctly anticipated that Trump would unambiguously lose the popular vote.

Meanwhile, my average forecast from the Bread and Peace model is $53.0 \pm 3.65$ percentage points, which is currently wrong by 4.9 points or, equivalently, by 1.33 ex ante standard errors and 1.87 ex post standard errors. Why is the Bread and Peace model proving unusually wrong about this year's election? Some potential explanations, such as voter suppression, may be particularly salient this year, but are unsatisfactory as explanations because they also apply to several other presidential elections captured in my dataset they are not particular to 2020, and so would be less credible as explanations of a 2020-specific modelling failure. Employing voter suppression as an example, I note that the data I use to fit the model include two elections predating the Civil Rights Acts of 1957 and 1960, and two more elections predating the Voting Rights Act of 1965, so the model is aware of at least 4 elections held with non-negligible voter suppression. As such, the estimates that come out of the fitted model already allow for some level of voter suppression, despite the model omitting voter suppression as an explicit factor.

In lieu of starting with a long list of dramatic-sounding factors playing into the 2020 election (voter suppression, COVID-19, Black Lives Matter, expanded postal voting and the US Postal Service, West Coast wildfires, dark money, small donors, online Russian influence operations, eligible potential voters circulating misinformation on social media, diplomatic deals orchestrated between Middle Eastern countries, leaked emails, etc. ad nauseam), one can instead narrow the field by calculating which past election the model was most wrong about, and asking which factor(s) that election shares with only the 2020 election. (This does, naturally, pose its own danger of overfitting.)

Of the 17 elections to which it was fitted, the model was most wrong about the 2000 election, where it overestimated VOTE by 6.3 percentage points, a far larger error than the 2.6-point ex post standard error and the model's second-worst error of 3.8 points for 1956. The major common factor I notice between the presidential elections of 2000 and 2020 is an impeached incumbent president. Donald Trump's impeachment, or at least the underlying current of scandal and outrage for which the impeachment may be a proxy, strikes me as a promising step towards explaining his loss ${ }^{\text {* }}$

More-prosaic explanations are possible. For instance, the Bread and Peace model might be correct to focus on economic voting, but wrong to assume that RDPI per capita is an adequate summary of how voters evaluate the economy. $G$ directly accounts for (changes in) personal income and inflation, but does not directly account for (un)employment, stock-market performance, income inequality, wealth inequality, or government borrowing rates. Adding variables such as the employment-to-population ratio to the model might therefore improve the model's fit to the 2020 election's results. (A brief experiment with replacing income growth in the model with growth in the employment-to-population ratio produced a model — Sweat and Peace? - with a looser fit to the 1952-2016 elections. Another model using growth in income and in the employment-to-population ratio, inevitably, had a closer fit than the Bread and Peace model, but the fit was only slightly closer, and a model with 3 regressors, 5 parameters, and only 17 observations surely raises overfitting concerns.)

\section{Conclusion}

This paper documents my replication of Douglas Hibbs's Bread and Peace model of how the popular vote in US presidential elections splits between the Democratic and Republican parties. Like Hibbs's, my fit of the model shows that personal-income growth and military fatalities in overseas wars precede pro-incumbent and anti-incumbent shifts in the two-party vote. With the data available as of October's end I develop forecasts of the model's inputs, then apply the model to this year's election, making a range of forecasts that 
suggest that current president Donald Trump would win the popular vote. The model forecasts that Trump shall get $49 \%-56 \%$ of the major-party vote, and the central forecasts specifically anticipate Trump getting $52 \%-54 \%$ of the major-party vote, in clear disagreement with the final polling averages of $45 \%-46 \%$ and the preliminary election result of about $48 \%$. Many factors could be invoked to explain the Bread and Peace model's undue optimism about Trump's 2020 performance; considering the model's past errors suggests that impeachment might be a key cause, or a proxy for a key cause, of Trump's underperformance in 2020.

\section{References}

[1] Douglas A Hibbs [2012]. Obama's Reelection Prospects under "Bread and Peace" Voting in the 2012 US Presidential Election. PS: Political Science 8 Politics, 45(4), 635-639.

[2] Defense Manpower Data Center and Statistical Information Analysis Division, US Department of Defense [2009]. Defense Casualty Analysis System Public Use File, 19502005. Accessed at https://catalog.archives.gov/OpaAPI/media/4734832/content/arcmedia/ electronic-records/rg-330/DCAS/PUF.DCAS19502005. DAT?download=true via https://catalog. archives.gov/id/4734832 on 3 September 2020.

[3] Defense Manpower Data Center and Statistical Information Analysis Division, US Department of Defense [2009]. Defense Casualty Analysis System Public Use File, 2006. Accessed at https: //catalog.archives.gov/OpaAPI/media/4734834/content/arcmedia/electronic-records/ rg-330/DCAS/PUF.DCAS2006.DAT?download=true via https://catalog.archives.gov/id/4734834 on 3 September 2020.

[4] iCasualties Iraq: iCasualties Home Page [2020]. Accessed at http://icasualties.org/ on 24 October 2020.

[5] Federal Reserve Economic Data [2020]. Population (B230RC0Q173SBEA). Accessed at https: //fred.stlouisfed.org/graph/fredgraph. csv?bgcolor=\%23e1e9f0\&chart_type=line\&drp=0\&fo= open\%20sans\&graph_bgcolor=\%23ffffff\&height=450\&mode=fred\&recession_bars=on\&txtcolor= $\% 23444444 \& t s=12 \& t t s=12 \& w i d t h=1168 \& n t=0 \& t h u=0 \& \operatorname{trc}=0 \&$ show_legend=yes\&show_axis_titles= yes\&show_tooltip=yes\&id=B230RC0Q173SBEA\&scale=left\&cosd=1947-01-01\&coed=2020-07-01\& line_color $=\% 234572 a 7 \& l i n k \_v a l u e s=f a l$ se\&line_style=solid\&mark_type=none\&mw $=3 \& l w=2 \&$ ost $=-99999 \& o e t=99999 \& m a=0 \& f m l=a \& f q=Q u a r t e r l y \& f a m=a v g \& f g s t=l i n \& f g s n d=2020-02-01 \&$ line_index=1\&transformation=lin\&vintage_date=2020-11-09\&revision_date=2020-11-09\&nd= 1947-01-01 via https://fred.stlouisfed.org/series/B230RC0Q173SBEA on 9 November 2020.

[6] US Census Bureau [2000]. Historical National Population Estimates: July 1, 1900 to July 1, 1999. Accessed at https://www2.census.gov/programs-surveys/popest/tables/1900-1980/national/ totals/popclockest.txt via https://www.census.gov/data/tables/time-series/demo/popest/ pre-1980-national.html on 31 August 2020.

*Just as Donald Trump's impeachment might be merely a signal rather than a cause of electoral underperformance, Bill Clinton's impeachment may not have directly caused the Democrats' underperformance in the 2000 presidential election. Impeachment proceedings against Clinton began 4 weeks before the midterm elections of 1998, but did not obviously hurt Clinton's party in those elections, given that his party gained 5 House seats [27. The public in fact appeared to react more negatively to the proceedings themselves than to Clinton's sexual misbehaviour, a meta-backlash for which scholars proposed several reasons. Voters viewed the proceedings along partisan lines and as a partisan exercise 28, 29, 27; they interpreted Clinton's sexual misconduct as a reflection on his personal character rather than on his competence as a politician 28] 29]; and even before Clinton confessed, most voters reckoned that he had had sex with Monica Lewinsky and lied under oath about it, and so Clinton's confession and Kenneth Starr's investigation revealed little information that was new and significant to voters 28, 29. A natural question that follows is why Clinton's misdeeds and impeachment would have hurt Al Gore's performance in 2000 despite their minimal impact on Democratic candidates in 1998. One possibility is that the impact of the scandal and impeachment in 2000 was purely indirect; rather than affecting voters, it affected $\mathrm{Al}$ Gore and his campaign strategy, driving him to avoid Democratic partisan appeals [30] and play down his association with Clinton and Clinton's impressive economic record 31 32. 
[7] US Census Bureau [2011]. Monthly Intercensal Resident Population Estimates for the United States: April 1, 2000 to July 1, 2010. Accessed at https://www2.census.gov/programs-surveys/popest/ datasets/2000-2010/intercensal/national/us-est00int-tot.csv via https://www.census . gov/data/datasets/time-series/demo/popest/intercensal-2000-2010-national.html on 2 September 2020 .

[8] US Census Bureau [2020]. Monthly Population Estimates for the United States: April 1, 2010 to December 1, 2020 (NA-EST2019-01). Accessed at https://www2.census.gov/programs-surveys/ popest/tables/2010-2019/national/totals/na-est2019-01.xlsx via https://www.census.gov/ data/tables/time-series/demo/popest/2010s-national-total.html on 3 September 2020.

[9] Federal Reserve Economic Data [2020]. Real Disposable Personal Income: Per Capita (A229RX0). Accessed at https://fred.stlouisfed.org/graph/fredgraph.csv?bgcolor $=\% 23 \mathrm{e} 1 \mathrm{e} 9$ f0\&chart_type=

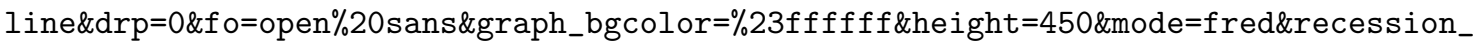
bars $=$ on\&txt color $=\% 23444444 \& t s=12 \& t t s=12 \& w i d t h=1168 \& n t=0 \& t h u=0 \& t r c=0 \& s h o w \_l e g e n d=y e s \&$ show_axis_titles=yes\&show_tooltip=yes\&id=A229RXo\&scale=left\&cosd=1959-01-01\&coed=

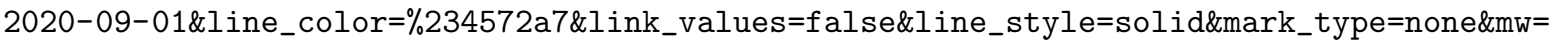
$3 \& 1 \mathrm{w}=2 \& 0 s t=-99999 \& 0 e t=99999 \& \mathrm{mma}=0 \& \mathrm{fml}=a \& f q=$ Monthly\&f am=avg\&f $g s t=1$ in\&f $g s n d=2020-02-01 \&$ line_index=1\&transformation=lin\&vintage_date=2020-11-09\&revision_date=2020-11-09\&nd= 1959-01-01 via https://fred.stlouisfed.org/series/A229RX0 on 9 November 2020.

[10] Federal Reserve Economic Data [2020]. Real Disposable Personal Income: Per Capita (A229RX0Q048SBEA). Accessed at https://fred.stlouisfed.org/graph/fredgraph.csv?bgcolor= $\% 23 \mathrm{e} 1 \mathrm{e} 9 \mathrm{f} 0 \&$ chart_type $=$ ine\&drp $=0 \& f \mathrm{f}=0 \mathrm{pen} \% 20$ sans\&graph_bgcolor $=\% 23 \mathrm{ffffff} \&$ height $=450 \&$ mode $=$ fred\&recession_bars $=$ on\&txtcolor $=\% 23444444 \& t s=12 \& t t s=12 \& \mathrm{width}=1168 \& n t=0 \&$ thu $=0 \&$ trc=0\&show_legend=yes\&show_axis_titles=yes\&show_tooltip=yes\&id=A229RX0Q048SBEA\&scale= left\&cosd=1947-01-01\&coed=2020-07-01\&line_color=\%234572a7\&link_values=false\&line_ style=solid\&mark_type=none\&mw $=3 \& 1 \mathrm{w}=2 \&$ ost $=-99999 \&$ oet $=99999 \& \mathrm{mma}=0 \& \mathrm{fml}=\mathrm{a} \& \mathrm{f} q=$ Quarterl $\mathrm{y} \&$ fam=avg\&fgst=lin\&fgsnd=2020-02-01\&line_index=1\&transformation=lin\&vintage_date= 2020-11-09\&revision_date=2020-11-09\&nd=1947-01-01 via https://fred.stlouisfed.org/ series/A229RX0Q048SBEA on 9 November 2020.

[11] Federal Reserve Economic Data [2020]. Real personal income excluding current transfer receipts (W875RX1). Accessed at https://fred.stlouisfed.org/graph/fredgraph.csv?bgcolor=

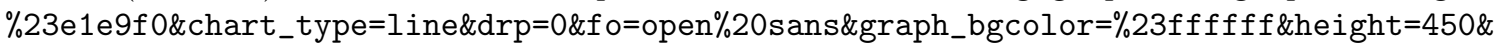
mode $=$ fred\&recession_bars $=$ on\&txtcolor $=\% 23444444 \& t s=12 \& t t s=12 \&$ width $=1168 \&$ int $=0 \&$ thu $=0 \&$ trc=0\&show_legend=yes\&show_axis_titles=yes\&show_tooltip=yes\&id=W875RX1\&scale=left\&

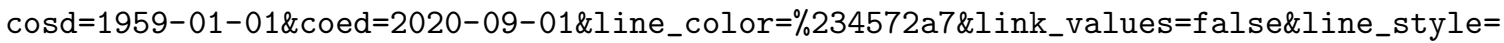
solid\&mark_type=none\&mw $=3 \& 1 \mathrm{w}=2 \& 0$ st $=-99999 \& o e t=99999 \& \mathrm{mma}=0 \& \mathrm{fml}=\mathrm{a} \& \mathrm{f} q=$ Monthly\&f am=avg\& fgst=lin\&fgsnd=2020-02-01\&line_index=1\&transformation=lin\&vintage_date $=2020-11-09 \&$ revision_date $=2020-11-09 \& n d=1959-01-01$ via https://fred.stlouisfed.org/series/W875RX1 on 9 November 2020.

[12] David Leip [2020]. Dave Leip's Atlas of U.S. Presidential Elections. Accessed at https:// uselectionatlas.org/RESULTS/ on 3 September 2020.

[13] Douglas A Hibbs Jr. [1982]. President Reagan's Mandate from the 1980 Elections: A Shift to the Right? American Politics Quarterly, 10(4), 387-420.

[14] Douglas A Hibbs Jr. [2000]. Bread and Peace voting in U.S. presidential elections. Public Choice, 104, 149-180.

[15] Douglas A Hibbs Jr. [2008]. Implications of the 'bread and peace' model for the 2008 US presidential election. Public Choice, 137, 1-10. 
[16] Douglas A Hibbs [2014]. 'Bread and Peace' Voting in US Presidential Elections: What Impact Rising Inequality? Slides presented at Deakin University, Melbourne, March 2014. Accessed at http://www . douglas-hibbs.com/HibbsArticles/HIBBS-PRESVOTE-SLIDES-MELBOURNE-Part1-2014-02-26.pdf on 29 January 2017.

[17] Robert Burns, Zeke Miller [2020]. US withdrawing thousands of troops from Iraq and Afghanistan. Associated Press, 10 September 2020. Accessed at https://apnews.com/ a6d9550ea12d041436dda09f30873f55 on 11 September 2020.

[18] U.S. Bureau of Economic Analysis [2019]. Appendix: Summary National Income and Product Accounts. In NIPA Handbook: Concepts and Methods of the U.S. National Income and Product Accounts, May 2019 update. Accessed at https://www.bea.gov/system/files/2019-05/Appendix.pdf on 23 September 2020.

[19] Alexander Arnon, Zheli He, Jon Huntley [2020]. Short-Run Economic Effects of the CARES Act. Penn Wharton Budget Model, 8 April 2020. Accessed at https://budgetmodel. wharton. upenn.edu/ issues/2020/4/8/short-run-effects-of-the-cares-act on 14 September 2020.

[20] U.S. Department of the Treasury [2020]. Treasury, IRS Announce Delivery of 159 Million Economic Impact Payments. 3 June 2020. Accessed at https://home.treasury.gov/news/press-releases/ sm1025 on 21 September 2020.

[21] CNNPolitics [2020]. What's in the $\$ 2$ trillion coronavirus stimulus bill. Cable News Network, 26 March 2020. Accessed at https://edition.cnn.com/2020/03/25/politics/ stimulus-package-details-coronavirus/index.html on 23 September 2020.

[22] U.S. Department of Labor [2020]. Unemployment Insurance Relief During COVID-19 Outbreak. Accessed at https://www.dol.gov/coronavirus/unemployment-insurance on 23 September 2020.

[23] Jan Hatzius, Alec Phillips, David Mericle, Spencer Hill, Daan Struyven, David Choi, Joseph Briggs, Blake Taylor, Ronnie Walker [2020]. Income Losses vs. Fiscal Stimulus: Estimating Second-Round Effects from the Virus Shock. Goldman Sachs, 29 April 2020. Accessed at https://www.gspublishing.com/content/research/en/reports/2020/04/29/ f421647d-b3da-4e1a-81ab-ba0870b7387d.html on 27 September 2020.

[24] Wikipedia [2020]. Nationwide opinion polling for the 2020 United States presidential election. Version of 17:46, 3 November 2020. Accessed at https://en.wikipedia.org/w/index.php?title=Nationwide_ opinion_polling_for_the_2020_United_States_presidential_election\&oldid=986903612 on 9 November 2020.

[25] FiveThirtyEight [2020]. 2020 Election Forecast | FiveThirtyEight. Version of 3 November 2020. Accessed at https://projects.fivethirtyeight.com/2020-election-forecast/ on 9 November 2020.

[26] Bloomberg [2020]. 2020 Presidential Election Results: Live Updates. Accessed at https://www. bloomberg.com/graphics/2020-us-election-results on 17 November 2020.

[27] Alan I Abramowitz [2001]. It's Monica, Stupid: The Impeachment Controversy and the 1998 Midterm Election [1998]. Legislative Studies Quarterly, 26(2), 211-226.

[28] Gary C Jacobson [1999]. Impeachment Politics in the 1998 Congressional Elections. Political Science Quarterly, 114(1), 31-51.

[29] Gary C Jacobson [2000]. Public Opinion and the Impeachment of Bill Clinton. British Elections 83 Parties Review, 10(1), 1-31.

[30] Gerald M Pomper [2001]. The 2000 Presidential Election: Why Gore Lost. Political Science Quarterly, 116(2), 201-223. 
[31] James E Campbell [2001]. The Referendum That Didn't Happen: The Forecasts of the 2000 Presidential Election. PS: Political Science and Politics, 34(1), 33-38.

[32] James E Campbell [2001]. An Evaluation of the Trial-Heat and Economy Forecast of the Presidential Vote in the 2000 Election. American Politics Research, 29(3), 289-296. 